\title{
Does the cleat model interfere with ankle sprain risk factors in artificial grass?
}

\author{
Diogo C.F. Silva ${ }^{\mathrm{a}}$, Rui Macedo ${ }^{\mathrm{b}}$, António Mesquita Montes ${ }^{\mathrm{b}}$, Rubim Santos ${ }^{\mathrm{c}}$, \\ João Paulo Vilas-Boas ${ }^{\mathrm{d}}$, Andreia S.P. Sousa ${ }^{\mathrm{b}, *}$ \\ ${ }^{\text {a }}$ Functional Sciences Department, School of Health, Polytechnic Institute of Porto, Center for Rehabilitation Research (CIR) - Center of Studies of Human Movement and \\ Activity, R. Dr. António Bernardino de Almeida, 400, 4200-072 Porto, Portugal \\ ${ }^{\mathrm{b}}$ Physiotherapy Department, School of Health, Polytechnic Institute of Porto, Center for Rehabilitation Research (CIR) - Center of Studies of Human Movement and Activity, \\ Rua Dr. António Bernardino de Almeida, 400, 4200-072 Porto, Portugal \\ ${ }^{\mathrm{c}}$ Physics Department, School of Health, Polytechnic Institute of Porto, Center for Rehabilitation Research (CIR) - Center of Studies of Human Movement and Activity, R. Dr. \\ António Bernardino de Almeida, 400, 4200-072 Porto, Portugal \\ ${ }^{\mathrm{d}}$ Faculty of Sport, CIFI2D, Porto Biomechanics Laboratory (LABIOMEP), University of Porto, R. Dr. Plácido Costa, 91, 4200-450 Porto, Portugal
}

\section{A R T I C L E I N F O}

\section{Keywords:}

Kinematic

Kinetic

Electromyography

Synthetic ground

Chronic ankle instability

\begin{abstract}
A B S T R A C T
Background: The cleats-surface interaction has been described as a possible risk factor for lateral ankle sprain. However, their interaction is still unknown in individuals with chronic ankle instability. The purpose of this study was to determine the influence of different soccer cleats on kinematic, kinetic and neuromuscular ankle variables on artificial grass in soccer players with and without chronic ankle instability.

Methods: Eighty-two amateur athletes divided in two groups: 40 with chronic ankle instability and 42 without chronic ankle instability. All subjects performed 2 series of 6 consecutive crossover jumps with dominant foot, each one with one of the four models of cleats (Turf, Artificial grass, Hard and Firm ground). Cleat and group main effect and interactions of kinematic, kinetic and neuromuscular variables were analyzed according to factorial repeated measures ANOVA.

Findings: No statistically significant cleat and group main effect and interactions were identified in kinematic, kinetic and electromyographic magnitude of the peroneal muscles. A main effect of the group was observed for peroneus longus activation time for TF model $(\mathrm{p}=0.010)$.

Interpretation: In soccer players, the contributor variables for ankle sprain were not influenced by the kind of soccer cleat used in a functional jump test on artificial grass. However, players with chronic ankle instability present delayed postural adjustments in peroneus longus with the TF model compared to players without chronic ankle instability.
\end{abstract}

\section{Introduction}

With $>265$ million practitioners worldwide (Kunz, 2007), modern soccer become faster, unpredictable and extremely competitive (Sterzing et al., 2009). The development of the ultimate third generation artificial grass fields held the possibility for more hours of practice (FIFA, n.d.; FIFA, n.d.) and the several modifications done in the cleats, such as the distribution and the geometry of the studs (Fig. 1) (Lees and Nolan, 1998), have contributed to the fulfillment of the player's needs (Conenello, 2010; Sterzing, 2016). Currently there are four types of cleats used in artificial grass fields: Turf (TF), Artificial grass (AG), Hard Ground (HG) and Firm Ground (FG). The TF and AG models are suitable for artificial fields, the HG model for hard natural or dirt soccer fields and the FG model is indicated for natural grass in good conditions (Conenello, 2010; Queen et al., 2008). Despite the recommendations stated for each model, most players select the cleat model based on its stability (Hennig, 2011) against ankle sprains (Silva et al., 2017a).

Ankle sprain represents $10-30 \%$ of all musculoskeletal disorders (Fong et al., 2007) and about 76\% in soccer (Garrick and Requa, 1988). A sudden and unexpected inversion/supination motion (Richie, 2001), with or without plantar flexion (Mok et al., 2011) is the most common injury mechanism (85\% of cases) (Morrison and Kaminski, 2007). It has been estimated that from all athletes that suffered an ankle sprain, 40-75\% may develop chronic ankle instability (CAI), characterized by

\footnotetext{
* Corresponding author.

E-mail addresses: dcs@ess.ipp.pt (D.C.F. Silva), rmacedo@ess.ipp.pt (R. Macedo), rss@ess.ipp.pt (R. Santos), jpvb@fade.up.pt (J.P. Vilas-Boas), asp@ess.ipp.pt (A.S.P. Sousa).
} 


\section{Studs}

Studs/sole
material

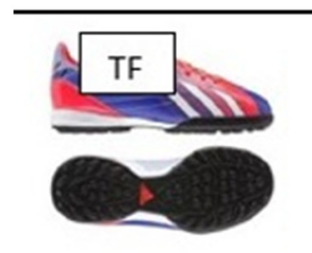

$\begin{aligned} & \text { Rubber studs and } \\ & \text { compliant sole }\end{aligned} \quad>55 \quad 6-7 \mathrm{~mm}$

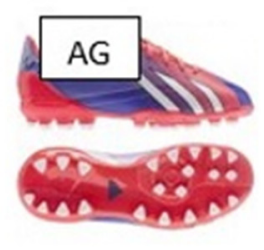

$22 \quad 8-10 \mathrm{~mm}$

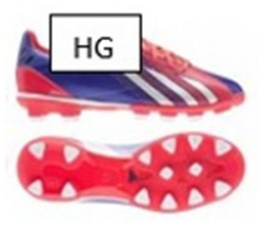

\section{Plastic studs and rigid plastic sole}

$14 \quad 10-12 \mathrm{~mm}$

\section{Prismatic}

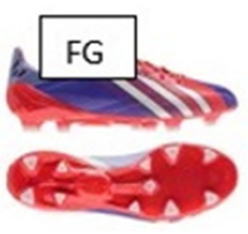

$11 \quad 10-12 \mathrm{~mm}$

Fig. 1. Cleat's characteristics

Legend: TF - Turf; AG - Artificial grass; HG - Hard ground; FG - Firm ground; mm - millimeters.

persistent residual pain, edema and reports of giving way and instability (Gribble et al., 2014; Hertel, 2002).

Despite the lack of consensus, several intrinsic risk factors for lateral ankle sprain (LAS) have been described: female gender (Doherty et al., 2014); taller and heavier athletes; ankle ligament instability; dominant limb (Beynnon et al., 2002); decreased dorsiflexion (Noronha et al., 2006); ankle alignment deformities (calcaneal varus); type of foot (cavus) (Morrison and Kaminski, 2007); increased center of pressure (COP) displacement (McKeon and Hertel, 2008; Munn et al., 2010); functional strength asymmetries of the ankle flexors (Fousekis et al., 2012); decreased evertor strength (Arnold et al., 2009), increased peroneal muscular activation time (Beynnon et al., 2002) and previous sprain history (Pourkazemi et al., 2014). However, only severity of initial sprain (grade II) is considered as a predictor for re-sprain (Pourkazemi et al., 2014). The fact that most individuals with a LAS episode will sustain at least one additional sprain, with many developing CAI (Gribble et al., 2016), and that this condition increase the risk of LAS, corroborates the need of studying athletes with CAI also (Silva et al., 2017a). On the other hand, extrinsic factors such as cleatsurface interaction have been studied (Silva et al., 2017b), highlighting the need of identifying an easily modifiable risk factor that help players to reduce different injuries risk. A systematic review demonstrated that different cleat models have been evaluated in terms of risk of injury in cases of calcaneal apophysitis, repeated impact injuries, and knee and ankle injuries related to increased joint loading (Silva et al., 2017b). However, only recently it has been demonstrated that in healthy athletes different cleat models aren't related to differences in ankle sprain risk factors (Silva et al., 2017a). Moreover, according to our knowledge, and despite deserving the attention of all sports and health professionals (Boer et al., 2014; Kemler et al., 2016), no study has evaluated the influence of different cleat models in ankle sprain risk factors in athletes with postural control deregulation such as CAI.

Therefore, the aim of the study is to evaluate the influence of different cleat models on variables related to the risk of ankle sprain in athletes with and without CAI. Specifically, postural alignment related variables, loading rate of vertical and lateral components of the ground's reaction forces; center of pressure (COP) displacement-related variables and neuromuscular variables (onset timing and magnitude of the peroneal muscle) were selected for analysis. Based on evidence that the cleat-surface traction must be enough to prevent slip and facilitate turning maneuvers (Conenello, 2010), but also that excessive fixation has been implicated in non-contact injuries during turning and cutting maneuvers associated to increased torque on lower extremity joint structures (Lambson et al., 1996), it can be hypothesized that the studs' number, distribution and height can significantly affect joint stability, expressed through kinetics, kinematics and muscle activity variables.

\section{Methods}

An experimental intra-subject study design was developed in a sample of federated amateur soccer players, with and without CAI.

\subsection{Participants}

Eighty-two male athletes aged between 18 and 30 years, from 32 of the 96 clubs of the Porto Football Association participated in the 
present study. The recruitment of the sample was conducted by electronic invitation to all clubs. The athletes who volunteered for the study have been included. The sample was divided in two groups based on the presence of CAI: 40 athletes were included in the group with CAI, and 42 in the without CAI group.

To participate in the present study athletes must had federated soccer practice in the last 5 seasons, as well a foot size of 41 . Participants assigned to the CAI group met the criteria set by the International Ankle Consortium (Gribble et al., 2014). To be included in the CAI group, athletes should have history of ankle sprains in the dominant limb for less than one year and respond "yes" in 5 or more questions regarding their dominant limb in the Ankle Instability Instrument (AII) (Docherty et al., 2006; Gribble et al., 2014) and presented a positive drawer test (Docherty et al., 2006; Gribble et al., 2014; van Dijk, 2002; Vries et al., 2010). Athletes were excluded if they presented one or more of the following criteria: history of surgery in both lower limbs, pathologies that directly affect the balance, conditions that alter peripheral sensory afferents, any type of neuro-musculoskeletal injury beyond ankle sprain in both lower limbs in the last year, and occurrence of ankle sprain in the last 3 months, due to the possibility of still being in an acute or subacute stage (Caffrey et al., 2009; McKeon et al., 2010).

Healthy control participants were selected according to the same exclusion criteria applied to the CAI group and were also excluded if they had history of ankle sprain.

The characteristics of the participants are presented on Table 1. It should be noted that both groups were comparable in age, body mass, height and have similar experience of official soccer practice (11 years) and hours of training in the current season $(7 \mathrm{~h} /$ week). The group with CAI presented on average 1.9 ankle sprains in the dominant foot, most of which (39.96\%) occurred $>12$ months ago (Table 1). Since decreased dorsiflexion could be a predictor of the occurrence of ankle sprain we also characterized participants regarding this variable (Noronha et al., 2006). The group with CAI presented decreased values comparing to the group without CAI.

The study was conducted according to the ethical norms of the Institutions involved and conformed to the Declaration of Helsinki, with informed consent from all participants.

\subsection{Instruments}

Anthropometric data were evaluated with a scale - Seca ${ }^{\circledR} 760(1 \mathrm{~kg}$

Table 1

Sample characterization. Significant differences were identified with a asterisk $(*)$.

\begin{tabular}{|c|c|c|c|c|}
\hline & & With CAI & Without CAI & $\mathrm{p}$ Value \\
\hline \multicolumn{2}{|l|}{ Age (years) - mean (SD) } & $21.4(2.97)$ & $21.3(2.63)$ & 0.853 \\
\hline \multicolumn{2}{|c|}{ Body mass $(\mathrm{Kg})$ - mean (SD) } & $68.8(4.91)$ & $69.0(7.19)$ & 0.846 \\
\hline \multicolumn{2}{|c|}{ Height (m) - mean (SD) } & $1.7(0.05)$ & $1.8(0.06)$ & 0.734 \\
\hline \multicolumn{2}{|c|}{ Dorsiflexion ROM (degrees) - mean (SD) } & $35.8(4.26)$ & $41.1(4.04)$ & $<0.001^{*}$ \\
\hline \multicolumn{2}{|c|}{$\begin{array}{l}\text { Official football practice } \\
\text { (years) - mean (SD) }\end{array}$} & $10.8(3.63)$ & $10.8(2.60)$ & 0.906 \\
\hline \multicolumn{2}{|l|}{$\begin{array}{l}\text { Training period (hours } \\
\text { per week) - mean } \\
\text { (SD) }\end{array}$} & $6.8(1.53)$ & $7.2(1.82)$ & 0.271 \\
\hline \multirow{3}{*}{$\begin{array}{l}\text { Cleat model preference } \\
\text { for play on artificial } \\
\text { grass }\end{array}$} & TF model & $3.7 \%$ & $0.0 \%$ & \multirow[t]{4}{*}{0.222} \\
\hline & AG model & $17.1 \%$ & $22.0 \%$ & \\
\hline & HG model & $14.6 \%$ & $11.0 \%$ & \\
\hline $\begin{array}{l}\text { - relative } \\
\text { frequencies }(\%)\end{array}$ & FG model & $13.4 \%$ & $18.3 \%$ & \\
\hline \multicolumn{2}{|c|}{$\begin{array}{l}\text { Number of sprains in the dominant foot - } \\
\text { mean (SD) }\end{array}$} & $1.9(1.64)$ & - & - \\
\hline \multirow{4}{*}{$\begin{array}{l}\text { How long ago did the } \\
\text { last sprain occur - } \\
\text { relative frequencies } \\
(\%)\end{array}$} & $3-6$ months & $7.58 \%$ & - & - \\
\hline & $6-12$ months & $20.08 \%$ & - & - \\
\hline & $12-24$ months & $32.58 \%$ & - & - \\
\hline & $>24$ months & $39.96 \%$ & - & - \\
\hline
\end{tabular}

accuracy), and a stadiometer - Seca ${ }^{\circledR} 222$ (1 mm accuracy) (SECA, 2014). Dorsiflexion range of motion was assessed with a fluid-filled inclinometer with $1^{\circ}$ increments (MIE Medical Research Ltd., Leeks, UK) (Rabin et al., 2015). To control the jump speed, an on-line digital metronome was used (www.metronomeonline.com).

The "Ankle Instability Instrument" was used to identify athletes with CAI. This instrument presents high values of test-retest reliability (ICC $=0.95$ ). Internal consistency reliability estimates (Cronbach alpha) for each factor and the total measure ranged from 0.74 to 0.83 (Docherty et al., 2006).

The ankle eversion/inversion range of motion was monitored with the Qualisys motion capture ${ }^{\circledast}$ system, with 4 cameras (Oqus 1 ) with an acquiring frequency of $100 \mathrm{~Hz}$ (Qualisys $A B$, Packhusgatan 6 S-411 13 Gothenburg Sweden) and $19 \mathrm{~mm}$ reflector markers. This instrument present an excellent intra-observer reliability (ICC $=0.90$ ) (Sinclair et al., 2012).

The ground reaction forces (GRF) signal was collected with a sampling frequency of $100 \mathrm{~Hz}$, with two Bertec $^{\circledR}$ FP4060-10/8 force platforms connected to a AM 6300 amplifier (Bertec Corporation, 6171 Huntley Road Suite J Columbus, U.S.A.) and to the Qualisys motion capture $^{\circledast}$ system. The instrument shows an excellent intra-observer reliability in jump assessments (ICC 0.92-0.98) (Hori et al., 2009). The platforms were covered with a 3rd generation artificial grass carpet $\left(6 \mathrm{~m}^{2}\right)$, composed of polyethylene fibers $(60-65 \mathrm{~mm})$ and filled with purified silica and rubber.

The electromyographic signal (EMG) of the peroneal muscles (main lateral stabilizers of the ankle during inversion) was monitored using a bioPLUX research wireless signal acquisition system (Plux Ltd., Portugal). The signals were collected at a sampling frequency of $1000 \mathrm{~Hz}$ and were pre-amplified in each electrode and then fed into a differential amplifier with an adjustable gain setting $(25-500 \mathrm{~Hz}$; common-mode rejection ratio: $110 \mathrm{~dB}$ at $50 \mathrm{~Hz}$, input impedance of $100 \mathrm{M} \Omega$ and gain of 1000). Self-adhesive silver chloride EMG electrodes were used in a bipolar configuration and with $20 \mathrm{~mm}$ between detection surface centers (Dahlhausen ${ }^{\circledR}$, Köln, Germany). The skin impedance was measured with an Electrode Impedance Checker (Noraxon USA, Inc.). The determination of the peroneus longus (PL) and peroneus brevis (PB) muscles' activation time through EMG signal presents an excellent intra-observer reliability (0.82-0.91) (Hopper et al., 1998).

Finally, the data processing and analysis were made using the following software: Matlab R2012a (The MathWorks Inc., Boston, USA) and Acqknowledge 3.9 (BIOPAC Systems, Inc. Goleta, USA).

\subsection{Procedures}

\subsubsection{Preparation of the participants}

The muscle belly skin surface of selected muscles and patella of the dominant limb was prepared to reduce the electrical resistance to $<5 \mathrm{k} \Omega$. The dominant limb was determined asking the participant to kick a ball, the dominant limb was considered the one that kicked the ball. For PL and PB muscles the electrodes were placed according to the SENIAM recommendations. These locations were confirmed by palpation, during the voluntary contraction of those muscles, always by the same researcher (physiotherapist, expert with 16 years of practice). The ground electrode was placed in the patella (Hermens et al., 2000). Three reflector markers with $19 \mathrm{~mm}$ of diameter were placed in the posterior face of the leg and on the shoe: (1) $2 \mathrm{~cm}$ below the popliteal fold in the medium point between the lateral and medial face, (2) over the Achilles tendon in the alignment of the two malleolus and (3) in the center of the posterior face of the shoe (Beynnon et al., 2001; Norkin and White, 2009; Silva et al., 2017a). All participants wore a new cleat (size 41), ensuring a distance of $0.5 \mathrm{~cm}$ between the longest toe and the front of the cleat.

\subsubsection{Data collection}

All the participants were submitted to a functional test adapted from 


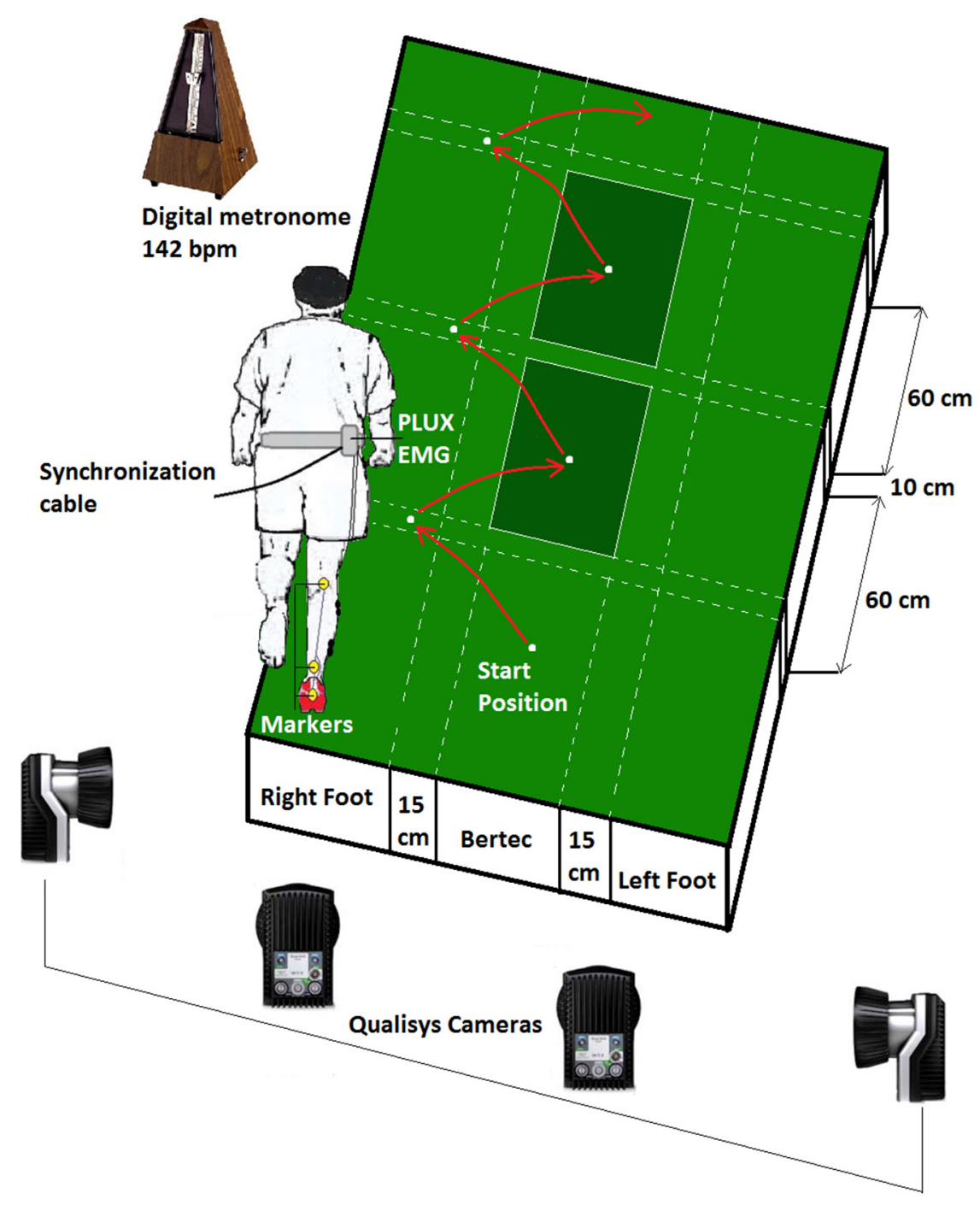

Fig. 2. Functional test

Legends: bpm - beats per minute; EMG - Electromyography.

the 6-m crossover test after $10 \mathrm{~min}$ of warm-up in the cycloergometer with $2 \%$ of the body weight and self-directed stretching exercises (Brown et al., 2012; Silva et al., 2017a). The participants performed 2 series of 6 consecutive crossover jumps with the dominant foot, at a cadence of 142 beats per minute (controlled by metronome) while wearing one of the four models of cleats (Turf, Artificial grass, Hard ground and Firm ground). A 2-minute resting period was set between each series (Caffrey et al., 2009; Docherty et al., 2005). The cadence adopted was based on the maximum cadence executed by active individuals in this kind of functional tests (Caffrey et al., 2009; Docherty et al., 2005). Participants carried out a series of trials for familiarization with the task, to memorize the execution speed and minimizing the effects of the learning process. To diminish the order effect, the sequence of the cleats was randomized. All possible sequences were written on several papers, which the participant himself selected from a bag. The paper selected was removed until there were no more papers left in the bag. All participants had to respect the distances indicated in Fig. 2 in their jumps. A trial was considered valid when the subject reached this distance in each jump with the defined cadence and land inside the force plate landmarks (Caffrey et al., 2009; Docherty et al., 2005).

\subsubsection{Data processing}

All variables were analyzed during the foot contact periods on force plates and the average values were used for analysis. The signal from the force platform was low pass filtered through a 4th order Butterworth filter of $15 \mathrm{~Hz}$ and was normalized to the body weight. The initial contact with the ground was defined as the instant where the value of the vertical component of the GRF was $>10 \mathrm{~N}$ (Brown et al., 2012). The loading rate of the vertical $(\mathrm{Fz})$ and medio-lateral $(\mathrm{Fx})$ components of the GRF was obtained by calculating the difference between the maximum and minimum values, divided by the time interval. The medio-lateral (COPx) and anteroposterior (COPy) displacements of the COP were calculated for each contact period. The medio-lateral (V_COPx) and antero-posterior (V_COPy) average speeds for the COP displacement were assessed by dividing the COP displacement by the time interval (Duarte and Freitas, 2010).

A 2nd order Butterworth low-pass filter of $6 \mathrm{~Hz}$ was applied to kinematic data. The total ankle eversion/inversion range of movement (ROM) was obtained through the difference between the maximum eversion and inversion the angle formed between the 'leg' segment and the 'hind foot' segment (Whatman et al., 2012).

The electromyographic signals were filtered using a zero-lag, second-order Butterworth filter with an effective band pass of 10 to $500 \mathrm{~Hz}$. The root mean square was calculated using a moving window of 20 samples (Schmid et al., 2010). The temporal analysis was made in relation to the instant of foot contact to the ground (T0). The timing of EMG onset was defined for each muscle as the beginning of the interval 


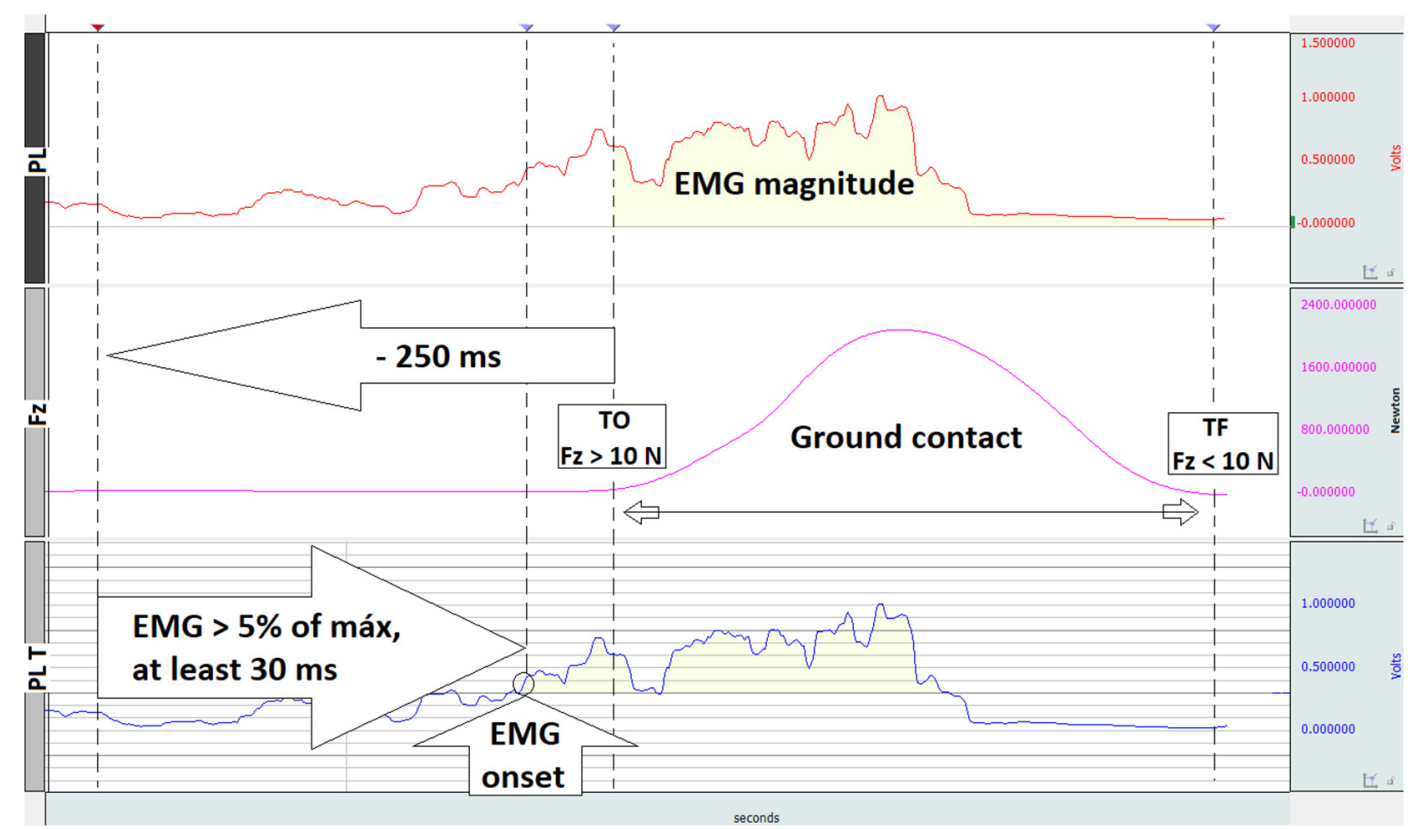

Fig. 3. EMG analysis procedure

Legends: TO - instant of foot contact to the ground; TF - instant when the foot leaves the ground; PL - peroneus longus; Fz - Vertical component of the ground reaction forces; PL T - timing analysis of peroneus longus; ms - milliseconds; EMG - Electromyography.

Table 2

Group and cleat model main effects and interactions of kinematic variables.

\begin{tabular}{|c|c|c|c|c|c|c|}
\hline \multicolumn{2}{|c|}{ Variables/cleat models } & \multicolumn{2}{|l|}{ Groups } & $\begin{array}{l}\text { Group cleat interaction } \\
p \text { Value } \\
(1-\beta)\end{array}$ & $\begin{array}{l}\text { Main effects of the group } \\
\text { p Value } \\
(1-\beta)\end{array}$ & $\begin{array}{l}\text { Main effects of the cleat models } \\
\text { p Value } \\
(1-\beta)\end{array}$ \\
\hline \multirow[t]{3}{*}{ ROM (degrees) } & $\mathrm{TF}$ & $7.4(4.90)$ & $5.9(3.24)$ & 0.257 & 0.255 & 0.263 \\
\hline & AG & $6.7(3.30)$ & $5.2(2.96)$ & $(0.359)$ & $(0.205)$ & $(0.354)$ \\
\hline & HG & $6.5(3.36)$ & $6.7(4.61)$ & & & \\
\hline \multirow{2}{*}{$\mathrm{COPx}(\mathrm{mm})$} & HG & 199.9 (132.91) & $175.8(126.86)$ & & & \\
\hline & FG & $186.5(109.82)$ & $181.0(125.00)$ & & & \\
\hline \multirow{4}{*}{ COPy (mm) } & $\mathrm{TF}$ & $143.6(48.39)$ & $158.9(76.67)$ & 0.480 & 0.451 & 0.380 \\
\hline & AG & $147.0(43.89)$ & $155.0(58.23)$ & $(0.229)$ & $(0.116)$ & $(0.278)$ \\
\hline & HG & $141.6(38.42)$ & $149.8(59.70)$ & & & \\
\hline & FG & $144.8(41.40)$ & $145.7(57.78)$ & & & \\
\hline $\mathrm{V}_{-} \mathrm{COPx}(\mathrm{mm} / \mathrm{s})$ & $\mathrm{TF}$ & 773.8 (531.61) & $657.6(503.22)$ & 0.224 & 0.714 & 0.763 \\
\hline \multirow{2}{*}{$\mathrm{V}_{-} \mathrm{COPy}(\mathrm{mm} / \mathrm{s})$} & HG & $525.52(140.41)$ & $580.9(249.33)$ & & & \\
\hline & FG & $527.40(181.46)$ & $547.0(212.92)$ & & & \\
\hline
\end{tabular}

of at least $30 \mathrm{~ms}$ where a value equal to or higher than $5 \%$ of maximum obtained in each trial was observed in a time window starting at $-250 \mathrm{~ms}$ in relation to T0 (Fig. 3) (Hodges and Bui, 1996; Nieuwenhuijzen et al., 2002; Shiratori and Latash, 2001). To allow us to look at the net effect of the stimulus in dynamic and cyclic tasks, averaged EMG magnitude of the active period was subtracted from the raw signal for the EMG onset. The timing of muscle onset was confirmed by visual inspection (Nieuwenhuijzen et al., 2002). The analysis of the magnitude of activation of the peroneal muscles was performed through the mean RMS of the EMG signal during the periods of contact with the platforms and was normalized to the signal obtained during maximal voluntary isometric contractions (MVIC) (Akhbari et al., 2007). MVIC were assessed with the participant in a supine position, knee extended, heel off the table and the foot in a slight plantar flexion. The resistance was manually applied always by the same researcher while the participant was encouraged verbally to execute their maximum eversion contraction (Kendall et al., 2005). For signal normalization, mean RMS of the interval between the second 2 and second 4 during each MVIC were used for analysis. The final values of the analysis (time and magnitude of activation) for each cleat were calculated considering the average of the 4 contacts of the participant on the platforms during the 2 jump repetitions.

\subsection{Statistics}

$P A S W^{\circledR}$ Statistics 20 software was used with a significance level of 
Table 3

Group and cleat model main effects and interactions of kinetic variables.

\begin{tabular}{|c|c|c|c|c|c|c|}
\hline \multicolumn{2}{|c|}{ Variables/cleat models } & \multicolumn{2}{|l|}{ Groups } & \multirow{2}{*}{$\begin{array}{l}\text { Group cleat interaction } \\
\text { p Value } \\
(1-\beta)\end{array}$} & \multirow{2}{*}{$\begin{array}{l}\text { Main effects of the group } \\
\text { p Value } \\
(1-\beta)\end{array}$} & \multirow{2}{*}{$\begin{array}{l}\text { Main effects of the cleat models } \\
\text { p Value } \\
(1-\beta)\end{array}$} \\
\hline & & $\begin{array}{l}\text { With } \\
\text { CAI } \\
\text { mean (SD) }\end{array}$ & $\begin{array}{l}\text { Without } \\
\text { CAI } \\
\text { mean (SD) }\end{array}$ & & & \\
\hline \multirow[t]{4}{*}{ LRVz (BW/s) } & $\mathrm{TF}$ & $2.37(0.47)$ & $2.57(0.78)$ & 0.575 & 0.241 & 0.050 \\
\hline & AG & $2.32(0.42)$ & $2.33(0.47)$ & $(0.189)$ & $(0.215)$ & $(0.641)$ \\
\hline & HG & $2.44(0.66)$ & $2.56(0.73)$ & & & \\
\hline & FG & $2.35(0.33)$ & $2.43(0.37)$ & & & \\
\hline \multirow[t]{4}{*}{ LRVx (BW/s) } & $\mathrm{TF}$ & $0.42(0.10)$ & $0.46(0.09)$ & 0.582 & 0.230 & 0.517 \\
\hline & AG & $0.44(0.10)$ & $0.46(0.13)$ & $(0.186)$ & $(0.223)$ & $(0.212)$ \\
\hline & HG & $0.43(0.10)$ & $0.45(0.08)$ & & & \\
\hline & FG & $0.43(0.11)$ & $0.44(0.09)$ & & & \\
\hline
\end{tabular}

0.05. The mean and median were used as measures of the central tendency, and the standard deviation and interquartile range as dispersion measures (Marôco, 2010).

The chi-square test was used to test an association between a cleat model preference and the groups with and without CAI. Regarding the kinematic, kinetic and neuromuscular variables, the main effect of the group and the cleat and related interactions were analyzed according to the factorial repeated measures ANOVA. The magnitude of the effects was accessed through the Cohen's $d$.

The Bonferroni correction was used for the post hoc analysis. TStudent test was used to compared sociodemographic data and the same cleat in different groups. Power analysis (1- $\beta$ ) was performed to give an indication of the power of hypothesis tests (Marôco, 2010).

\section{Results}

No statistical significant cleat and group main effects and interaction were observed in kinematic variables (Table 2).

No statistical significant cleat and group main effects and interaction were observed in the slope of Fz e Fx (Table 3).

While no statistical significant cleat and group main effects and interaction were observed in the EMG magnitudes and in the PB activation time (Table 4), a main effect of the group was observed for PL activation time for TF model ( $\mathrm{p}=0.010)$ with a moderate effect (Cohen's $d=0.60$ ). For this variable, the group with CAI presented a delayed activation time. No main effects of the cleat and no significant cleat-group interaction were observed.

\section{Discussion}

The results of the present study demonstrate delayed PL activation with the TF model in the group with CAI compared to the group without CAI. However, no interaction was observed between the cleat and the group demonstrating that the effect of the cleat seems to be independent from the effect of the group. Also, no statistically significant main effects and interactions were observed for the other kinematic, kinetic and neuromuscular variables. The results of the present study should be discussed under the following assumptions: 1) the low degree of unpredictability of the functional test adopted on the present study decreased the test difficulty (Borotikar et al., 2008); and 2) although we can't access to the particularities of intervention, all athletes participated in the present study underwent physical therapy after injury and were competing for at least 3 months without restriction. The effectiveness of proprioceptive training programs in reducing the rate of ankle sprains and improving motor control are well established (Schiftan et al., 2015) and may have been a key factor for the few differences between groups.

The absence of significant main effects and cleat-group interactions in ankle ROM as well COP related variables and vertical and mediolateral loading rates of the ground reaction forces could be explained by the fact that our test was performed with cleats, while the original crossover test was described barefoot (Caffrey et al., 2009; Docherty et al., 2005). The use of cleats may have provided greater comfort and ankle stability minimizing the functional deficits expected in the group with CAI (Rabello et al., 2014), even when this group presents decreased ankle dorsiflexion. In fact, restricted ankle dorsiflexion could

Table 4

Group and cleat model main effects and interactions of neuromuscular variables. Significant differences were identified with a asterisk (*).

\begin{tabular}{|c|c|c|c|c|c|c|}
\hline \multicolumn{2}{|c|}{ Variables/cleat models } & \multicolumn{2}{|l|}{ Groups } & \multirow{2}{*}{$\begin{array}{l}\text { Group cleat interaction } \\
\text { p Value } \\
(1-\beta)\end{array}$} & \multirow{2}{*}{$\begin{array}{l}\text { Main effects of the group } \\
\text { p Value } \\
(1-\beta)\end{array}$} & \multirow{2}{*}{$\begin{array}{l}\text { Main effects of the cleat models } \\
\text { p Value } \\
(1-\beta)\end{array}$} \\
\hline & & $\begin{array}{l}\text { With } \\
\text { CAI } \\
\text { mean (SD) }\end{array}$ & $\begin{array}{l}\text { Without } \\
\text { CAI } \\
\text { mean (SD) }\end{array}$ & & & \\
\hline \multirow[t]{4}{*}{ EMG_PL (\%) } & $\mathrm{TF}$ & $95.6(41.89)$ & $104.9(50.86)$ & 0.138 & 0.674 & 0.306 \\
\hline & AG & $103.0(48.14)$ & $95.4(32.71)$ & $(0.479)$ & $(0.070)$ & $(0.323)$ \\
\hline & HG & $102.6(54.24)$ & $94.5(33.86)$ & & & \\
\hline & FG & $94.1(40.81)$ & 99.7 (45.95) & & & \\
\hline \multirow[t]{4}{*}{ EMG_PB (\%) } & $\mathrm{TF}$ & $93.2(39.77)$ & $95.3(31.33)$ & 0.722 & 0.472 & 0.162 \\
\hline & AG & $90.4(31.67)$ & $93.8(29.07)$ & $(0.138)$ & $(0.110)$ & $(0.449)$ \\
\hline & HG & $89.7(30.41)$ & $93.0(27.69)$ & & & \\
\hline & FG & $86.8(29.11)$ & $91.9(27.18)$ & & & \\
\hline \multirow[t]{4}{*}{ AT_PL (ms) } & $\mathrm{TF}$ & $-5.3(74.48)$ & $-64.3(118.76)$ & 0.089 & $0.031^{*}$ & 0.598 \\
\hline & AG & $-45.7(74.08)$ & $-55.8(84.89)$ & $(0.552)$ & $(0.582)$ & $(0.180)$ \\
\hline & HG & $-28.9(85.16)$ & $-66.1(85.03)$ & & TF With $>$ Without $\mathrm{p}=0.010^{*}$ & \\
\hline & FG & $-38.6(79.56)$ & $-41.4(121.53)$ & & & \\
\hline \multirow[t]{4}{*}{ AT_PB (ms) } & $\mathrm{TF}$ & $-68.3(81.38)$ & $-71.6(109.90)$ & 0.488 & 0.757 & 0.814 \\
\hline & AG & $-84.5(86.56)$ & $-67.0(88.14)$ & $(0.053)$ & $(0.061)$ & $(0.111)$ \\
\hline & HG & $-64.9(81.88)$ & $-76.8(81.26)$ & & & \\
\hline & FG & $-69.1(95.14)$ & $-70.7(88.48)$ & & & \\
\hline
\end{tabular}


lead to an abnormal lower extremity biomechanics during closed chain exercise (Dill et al., 2014), however our kinematic results didn't confirm this idea. Since we didn't evaluate the passive full ROM in other directions we can't assure that they are not in the origin of the non-existence differences in kinematic and kinetic variables. Future studies should evaluate these variables. The non-existence of a main effect of the cleat for the above mention variables together with the fact that during the stance phase the players achieved in average a functional ROM around $13 \%$ to $25 \%$ of the total ROM (Dubin et al., 2011), may suggest an appropriate dynamic control for the task. However, it should be noted that in the present study the degree of ankle inversion/eversion was calculated as the total difference, being not possible to identify if the movement occurred in the last degrees of inversion and thus be considered as more dangerous (Morrison and Kaminski, 2007).

Based on the evidence that cleats with studs that do not fully penetrate the artificial grass lead to increased instability (Clarke and Carré, 2010), increased values of COP related variables were expected in the present study in cleats with this feature. However, there wasn't observed a main effect of the cleat over these variables, revealing that athletes with and without CAI are able to deal with the postural challenges that different cleats can impose (Buchanan et al., 2008; Caffrey et al., 2009; Docherty et al., 2005). While similar results have been obtained by a recent study which used a similar sample of players without CAI (Silva et al., 2017a), the results in CAI are more surprising, since wasn't found significant interaction between cleats and the group. This could be due to the dry condition and the perfect state of the artificial grass. These particularities could have uniformized the cleat models' behaviour, allowing full penetration to the cleat with higher studs (HG and FG) and sufficient traction to the models with lower studs (TF and AG) (Silva et al., 2017a). Also, considering the evidence demonstrating postural control deficits in joints proximal to ankles with CAI (Bullock-Saxton, 1994; Caulfield and Garrett, 2002; Hertel and Olmsted-Kramer, 2007), future studies dedicated to the kinematic analysis of whole body are required to verify if the absence of differences in COP related variables are related to hip or trunk compensatory strategies.

Although some authors believe that increased vertical impact loads compared to mediolateral direction may allow the ankle joint to remain more stable avoiding excessive inversion forces (Dayakidis and Boudolos, 2006), no statistical significant main effects and interactions were observed, which agrees with the results obtained in the evaluation of healthy soccer players, that used the side hop test alternatively to the cross over in a very similar methodology (Silva et al., 2017a). In fact, it is possible that structurally different cleat models imposed different mechanical traction when assessed with mechanical instruments, but similar biomechanical traction when assessed in real conditions with soccer players in the same playing field (Sterzing et al., 2008). It has been argued that the playing fields are more determinant that the cleat models for identifying differences between models' mechanical properties (Villwock et al., 2009). These results contrast with studies associating higher studs with higher traction indices and consequently an increased risk of injury (Lake, 2000; Queen et al., 2008; Sterzing et al., 2009).

In the present study, no statistical main effects and interactions were observed in EMG magnitude of peroneal muscles. Despite the divergence of these results regarding peroneal strength deficits in individuals with CAI (Hartsell and Spaulding, 1999; Mattacola and Dwyer, 2002; McKnight and Armstrong, 1997; Pontaga, 2004; Wilkerson et al., 1997), the results of the present study indicate that athletes with CAI present no impairments in the magnitude of compensatory and accompanied postural adjustments. Despite both groups presented peroneal onset timings related to feedforward mechanisms, delayed activation of PL was observed in the TF model in CAI group (almost $60 \mathrm{~ms}$ of delay). Interestingly, this difference is only noticed with the cleats (TF model) that practically no athlete is accustomed to play with. According to Hennig (2011) neuromuscular adaptations to the cleats lead athletes to achieve a better motor performance with the models they are familiarized. In the present study the effect of the nonfamiliarization phenomenon was only observed in the CAI group (Hennig, 2011), revealing an increased difficulty to deal with new conditions. In another perspective, it should be considered that TF model presents the most compliant sole of all models studied, which could lead to higher foot segments mobility and interfere with ankle stability, particularly in the more vulnerably group (CAI). Future studies are required to confirm this hypothesis.

It should be noted that despite a main effect of the group for PL onset timing, this wasn't accompanied by a main effect of the group in kinematic and kinetic variables for the functional test performed, probably in more demanding tasks the differences observed in muscle activation timings could interfere with kinematic and kinetic variables increasing the risk of injury. Future studies involving more demanding postural tasks and assessing also other ankle muscles (e.g. tibialis anterior and soleus) are needed to confirm this hypothesis. It should be also considered the low observed power (1- $\beta$ ) obtained in the present study for the kinematic and kinetic variables future studies with higher sample are required to confirm our results.

Also, considering the limitations previously stated, future studies should analyse the influence of cleats on wet artificial grass fields, possibly with a few years of use, using full body kinematics, and evaluating dynamic tasks with some degree of unpredictability. It should be also considered that the interpretation of our results was based on the assumption that mechanical characteristics of the artificial grass maintained constant through the entire experiments, confirmed by an expert technician. However, because some variability may have occurred, future studies are required to assess this issue.

\section{Conclusion}

The findings obtained in the present study indicate that in soccer players, the contributor variables for ankle sprain were not influenced by the kind of soccer cleat in a functional test on a third-generation artificial grass. However, players with CAI present delayed postural adjustments in PL muscle with the TF model compared to players without CAI. The authors thank Adidas Portugal and Relvados e Equipamentos Desportivos Lda for their support.

\section{References}

Akhbari, B., Ebrahimi, T.E., Salavati, M., Farahini, H., Sanjari, M., 2007. Reliability of timing of muscle activity measurements of ankle musculature in reaction to various angles of sudden external oblique perturbation. RJMS. 13, 15-22.

Arnold, B.L., Linens, S.W., SJdl, Motte, Ross, S.E., 2009. Concentric evertor strength differences and functional ankle instability: a meta-analysis. J. Athl. Train. 44 (6), $653-662$.

Beynnon, B.D., Renstrom, P.A., Alosa, M.A., Baumhauer, J.F., Vacek, P.M., 2001. Ankle ligament injury risk factors: a prospective study of college athletes. J. Orthop. Res. $19,213-220$.

Beynnon, B.D., Murphy, D.F., Alosa, D.M., 2002. Predictive factors for lateral ankle sprains: a literature review. J. Athl. Train. 37 (4), 376-380.

Boer, A.S.D., Schepers, T., Panneman, M., 2014. JM, Beeck EFV, Lieshout EMV. Health care consumption and costs due to foot and ankle injuries in the Netherlands, 1986-2010. BMC Musculoskelet. Disord. 15 (128), 1-10.

Borotikar BS, Newcomer R, Koppes R, McLean SG. Combined effects of fatigue and decision making on female lower limb landing postures: central and peripheral contributions to ACL injury risk. Clin Biomech (Bristol, Avon). 2008;23(1):81-92.

Brown C, Bowser B, Simpson KJ. Movement variability during single leg jump landings in individuals with and without chronic ankle instability. Clin Biomech (Bristol, Avon). 2012;27(1):52-63.

Buchanan, A.S., Docherty, C.L., Schrader, J., 2008. Functional performance testing in participants with functional ankle instability and in a healthy control group. J. Athl. Train. 43 (4), 342-346.

Bullock-Saxton JE. Local sensation changes and altered hip muscle function following severe ankle sprain. Physical therapy. 1994;74(1):17-28; discussion -31 .

Caffrey, E., Docherty, C.L., Schrader, J., Klossner, J., 2009. The ability of 4 single-limb hopping tests to detect functional performance deficits in individuals with functional ankle instability. J Orthop Sports Phys Ther. 39 (11), 799-806.

Caulfield, B.M., Garrett, M., 2002. Functional instability of the ankle: differences in patterns of ankle and knee movement prior to and post landing in a single leg jump. Int. J. Sports Med. 23 (1), 64-68. 
Clarke, J.D., Carré, M.J., 2010. Improving the performance of soccer boots on artificial and natural soccer surfaces. Procedia Eng. 2 (2), 2775-2781.

Conenello RM. Soccer. 2010. In: Athletic Footwear and Orthoses in Sports Medicine [Internet]. New York: Springer; (239-46).

Dayakidis, M.K., Boudolos, K., 2006. Ground reaction force data in functional ankle instability during two cutting movements. Clin. Biomech. 21 (4), 405-411.

van Dijk, C.N., 2002. Management of the sprained ankle. Br. J. Sports Med. 36 (2), 83-84.

Dill, K.E., Begalle, R.L., Frank, B.S., Zinder, S.M., Padua, D.A., 2014. Altered knee and ankle kinematics during squatting in those with limited weight-bearing-lunge ankledorsiflexion range of motion. J. Athl. Train. 49 (6), 723-732.

Docherty, C.L., Arnold, B.L., Gansneder, B.M., Hurwitz, S., Gieck, J., 2005. Functionalperformance deficits in volunteers with functional ankle instability. J. Athl. Train. 40, $30-34$.

Docherty, C.L., Gansneder, B.M., Arnold, B.L., Hurwitz, S.R., 2006. Development and reliability of the ankle instability instrument. J. Athl. Train. 41 (2), 154-158.

Doherty, C., Delahunt, E., Caulfield, B., Hertel, J., Ryan, J., Bleakley, C., 2014. The incidence and prevalence of ankle sprain injury: a systematic review and meta-analysis of prospective epidemiological studies. Sports Med. 44 (1), 123-140.

Duarte, M., Freitas, S.M.S.F., 2010. Revisão sobre posturografia baseada em plataforma de forca para avaliação do equilíbrio. Rev Bras Fisioter. 14 (3), 183-192.

Dubin, J.C., Comeau, D., McClelland, R.I., Dubin, R.A., Ferrel, E., 2011. Lateral and syndesmotic ankle sprain injuries: a narrative literature review. Journal of chiropractic medicine. 10 (3), 204-219.

FIFA. FIFA Quallity concept for Football Turf 2012 [cited 2012 2013]. Available from: http://www.fifa.com.

FIFA. FIFA - Quality concept for football turf 2009 [cited 201323 March 2013]. Available from: http://www.fifa.com.

Fong, D., Hong, Y., Chan, L., Yung, P., Chan, K., 2007. A systematic review on ankle injury and ankle sprain in sports. Sports Med. 37 (1), 73-94.

Fousekis, K., Tsepis, E., Vagenas, G., 2012. Intrinsic risk factors of noncontact ankle sprains in soccer. Am. J. Sports Med. 40 (8), 1842-1850.

Garrick, J.G., Requa, R.K., 1988. The epidemiology of foot and ankle injuries in sports. Clin. Sports Med. 7 (1), 29-36.

Gribble, P.A., Delahunt, E., Bleakley, C.M., Caulfield, B., Docherty, C.L., Fong, D.T.-P. et al., 2014. Selection criteria for patients with chronic ankle instability in controlled research: a position statement of the international ankle consortium. J. Athl. Train. 49 (1), 121-127.

Gribble, P.A., Bleakley, C.M., Caulfield, B.M., Docherty, C.L., Fourchet, F., Fong, D.T., et al., 2016. Evidence review for the 2016 International Ankle Consortium consensus statement on the prevalence, impact and long-term consequences of lateral ankle sprains. Br. J. Sports Med. 50 (24), 1496-1505.

Hartsell, H.D., Spaulding, S.J., 1999. Eccentric/concentric ratios at selected velocities for the invertor and evertor muscles of the chronically unstable ankle. Br. J. Sports Med. 33 (4), 255-258.

Hennig, E.M., 2011. The influence of soccer shoe design on player performance and injuries. Res Sports Med. 19 (3), 186-201.

Hermens, H.J., Freriks, B., Disselhorst-Klug, C., Rau, G., 2000. Development of recommendations for SEMG sensors and sensor placement procedures. J. Electromyogr. Kinesiol. 10, 361-374.

Hertel, J., 2002. Functional anatomy, pathomechanics, and pathophysiology of lateral ankle instability. J. Athl. Train. 37 (4), 364-375.

Hertel, J., Olmsted-Kramer, L.C., 2007. Deficits in time-to-boundary measures of postural control with chronic ankle instability. Gait Posture. 25 (1), 33-39.

Hodges, P.W., Bui, B.H., 1996. A comparison of computer-based methods for the determination of onset of muscle contraction using electromyography. Electroencephalogr. Clin. Neurophysiol. 101, 511-519.

Hopper, D., Allison, G., Fernandes, N., O'Sullivan, L., Wharton, A., 1998. Reliability of the peroneal latency in normal ankles. Clin. Orthop. Relat. Res. 350, 159-165.

Hori, N., Newton, R.U., Kawamori, N., McGuigan, M.R., Kraemer, W.J., Nosaka, K., 2009. Reliability of performance measurements derived from ground reaction force data during countermovement jump and the influence of sampling frequency. J Strength Cond Res. 23 (3), 874-882.

Kemler E, Krist MR, Gl van de Port I, Hoes AW, de Wit GA, Backx FJG. Economic Evaluation of a Soft Ankle Brace Compared to Tape in Acute Lateral Ankle Ligamentous Sprains. Clin Res Foot Ankle. 2016;04(04).

Kendall, F.P., McCreary, E.K., Provance, P.G., Rodgers, M.M., Romani, W.A., 2005. Muscles, Testing and Function: With Posture and Pain, 5 ed. Lippincott Williams \& Wilkins, Baltimore, MD.

Kunz, H., 2007 July. Big count - 265 million playing football. FIFA Magazine. 10-15.

Lake, M.J., 2000. Determining the protective function of sports footwear. Ergonomics. 43 (10), 1610-1621.

Lambson, R.B., Barnhill, B.S., Higgins, R.W., 1996. Football cleat design and its effect on anterior cruciate ligament injuries. A three-year prospective study. Am. J. Sports Med. 24 (2), 155-159.

Lees, A., Nolan, L., 1998. The biomechanics of soccer: a review. J. Sports Sci. 16 (3), 211-234.

Marôco J. Análise Estatistica com o PASW statistics. Pêro Pinheiro 2010.
Mattacola, C.G., Dwyer, M.K., 2002. Rehabilitation of the ankle after acute sprain or chronic instability. J. Athl. Train. 37 (4), 413-429.

McKeon, P., Hertel, J., 2008. Systematic review of postural control and lateral ankle instability, part II: is balance training clinically effective? J. Athl. Train. 43 (3), 305-315.

McKeon, P.O., Booi, M.J., Branam, B., Johnson, D.L., Mattacola, C.G., 2010. Lateral ankle ligament anesthesia significantly alters single limb postural control. Gait Posture. 32 (3), 374-377.

McKnight, C.M., Armstrong, C.W., 1997. The role of ankle strength in functional ankle instability. J. Sport Rehabil. 6 (1), 21-29.

Mok, K.M., Fong, D.T., Krosshaug, T., Engebretsen, L., Hung, A.S., Yung, P.S., et al., 2011. Kinematics analysis of ankle inversion ligamentous sprain injuries in sports: 2 cases during the 2008 Beijing Olympics. Am. J. Sports Med. 39 (7), 1548-1552.

Morrison, K.E., Kaminski, T.W., 2007. Foot characteristics in association with inversion ankle injury. J. Athl. Train. 42 (1), 135-142.

Munn, J., Sullivan, S.J., Schneiders, A.G., 2010. Evidence of sensorimotor deficits in functional ankle instability: a systematic review with meta-analysis. J. Sci. Med. Sport 13 (1), 2-12.

Nieuwenhuijzen, P.H.J.A., Gruneberg, C., Duysens, J., 2002. Mechanically induced ankle inversion during human walking and jumping. J. Neurosci. Methods 117, 133-140.

Norkin, C.C., White, D.J., 2009. Measurement of Joint Motion: A Guide to Goniometry, 4th ed. F.A. Davis Company, Philadelphia.

Noronha, M., Refshauge, K.M., Herbert, R.D., Kilbreath, S.L., 2006. Do voluntary strength, proprioception, range of motion, or postural sway predict occurrence of lateral ankle sprain? Br. J. Sports Med. 40, 824-828.

Pontaga I. Ankle joint evertor-invertor muscle torque ratio decrease due to recurrent lateral ligament sprains. Clin Biomech (Bristol, Avon). 2004;19(7):760-2.

Pourkazemi, F., Hiller, C.E., Raymond, J., Nightingale, E.J., Refshauge, K.M., 2014. Predictors of chronic ankle instability after an index lateral ankle sprain: a systematic review. J. Sci. Med. Sport 17 (6), 568-573.

Queen, R.M., Charnock, B.L., Garrett Jr., W.E., Hardaker, W.M., Sims, E.L., Moorman 3rd., C.T., 2008. A comparison of cleat types during two football-specific tasks on FieldTurf. Br. J. Sports Med. 42 (4), 278-284 (discussion 84).

Rabello, L.M., Macedo, C.S.G., Oliveira, M.R., Fregueto, J.H., Camargo, M.Z., Lopes, L.D., et al., 2014. Relação entre testes funcionais e plataforma de força nas medidas de equilíbrio em atletas. Rev. Bras. Med. Esporte 20 (3), 219-222.

Rabin, A., Kozol, Z., Spitzer, E., Finestone, A.S., 2015. Weight-bearing ankle dorsiflexion range of motion-can side-to-side symmetry be assumed? J. Athl. Train. 50 (1), 30-35.

Richie, D.H., 2001. Functional instability of the ankle and the role of neuromuscular control: a comprehensive review. J Foot Ankle Surg 40, 240-252.

Schiftan, G.S., Ross, L.A., Hahne, A.J., 2015. The effectiveness of proprioceptive training in preventing ankle sprains in sporting populations: a systematic review and metaanalysis. J. Sci. Med. Sport 18 (3), 238-244.

Schmid, S., Moffat, M., Gutierrez, G.M., 2010. Effect of knee joint cooling on the elec tromyographic activity of lower extremity muscles during a plyometric exercise. J. Electromyogr. Kinesiol. 20, 1075-1081.

SECA. Catalog 2014. Seca - Precision for health 2014.

Shiratori, T., Latash, M.L., 2001. Anticipatory postural adjustments during load catching by standing subjects. Clin. Neurophysiol. 112, 1250-1265.

Silva, D.C.F., Santos, R., Paulo V-B, J., Macedo, R., Montes, A., ASP, Sousa, 2017a. The influence of different soccer cleat type on kinetic, kinematic and neuromuscular ankle variables in artificial turf. Footwear Sci. 9 (1), 1-11.

Silva, D.C.F., Santos, R., Vilas-Boas, J.P., Macedo, R., Montes, A.M., Sousa, A.S.P., 2017b. Influence of cleats-surface interaction on the performance and risk of injury in soccer: a systematic review. Appl Bionics Biomech. 1-15.

Sinclair, J., Taylor, P.J., Greenhalgh, A., Edmundson, C.J., Brooks, D., Hobbs, S.J., 2012. The test-retest reliability of anatomical co-ordinate axes definition for the quantification of lower extremity kinematics during running. J Hum Kinet. 35, 15-25.

Sterzing, T., 2016. Soccer boots and playing surfaces. In: Strudwick, T. (Ed.), Soccer Science, 1 ed. Human Kinetics, Champaign, IL, USA, pp. 179-202.

Sterzing T, Müller C, Schwanitz S, Odenwald S, Milani TL, editors. Discrepancies between mechanical and biomechanical measurements of soccer shoe traction on artificial turf Symposium of the International Society of Biomechanics in Sports; 2008; Seoul Korea.

Sterzing, T., Müller, C., Hennig, E.M., Milani, T.L., 2009. Actual and perceived running performance in soccer shoes: a series of eight studies. Footwear Sci. 1 (1), 5-17.

Villwock, M.R., Meyer, E.G., Powell, J.W., Fouty, A.J., Haut, R.C., 2009. Football playing surface and shoe design affect rotational traction. Am. J. Sports Med. 37 (3), 518-525.

Vries, J.S., Kerkhoffs, G.M., Blankevoort, L., Dijk, C.N., 2010. Clinical evaluation of a dynamic test for lateral ankle ligament laxity. Knee Surg. Sports Traumatol. Arthrosc. 18 (5), 628-633.

Whatman, C., Hume, P., Hing, W., 2012. Kinematics during lower extremity functional screening tests in young athletes - are they reliable and valid? Phys Ther Sport. 1-7.

Wilkerson, G.B., Pinerola, J.J., Caturano, R.W., 1997. Invertor vs. evertor peak torque and power deficiencies associated with lateral ankle ligament injury. J Orthop Sports Phys Ther. 26 (2), 78-86. 